\title{
$\Omega$
}

Paraskevi Katsaounou' ${ }^{1}$, Stefan Frent ${ }^{2}$

(1]

${ }^{1}$ First ICU Dept, Evaggelismos Hospital, National and Kapodistrian University of Athens, Athens,

Greece.

2Dept of Pulmonology, University of Medicine and Pharmacy "Victor Babes", Timişoara, Romania.

\section{The ERS-industry fellowship: a tale of two experiences}

\section{Introduction}

Over the past few years, early career members of the European Respiratory Society (ERS) have expressed an interest in gaining exposure to industry, to complement their experience in the academic sector as well as to widen their career perspectives.

Effectively interfacing the pharmaceutical industry and practising physicians to improve patient care is a goal with enormous benefit. Achieving this has never been a smooth ride. Focusing on mechanisms for improving research/ clinical collaborations between industry and academia, and in line with this identified need, the ERS developed a collaborative Fellowship in Industry programme that offers the opportunity to undertake a fellowship in the European respiratory pharmaceutical industry.

A successful collaboration has been in place with Novartis since 2015 and opportunities for 12-month fellowships are available through a yearly call. Fellowship recipients get to provide their input as scientific and medical experts in the field of respiratory drug development, fostering their knowledge and skills in a pharmaceutical setting. Both MDs and PhDs in life sciences with clinical experience can apply for this fellowship, which is currently based at Novartis headquarters in Basel, Switzerland.

This piece spotlights our experiences as the first two recipients of the ERS fellowship at Novartis in Respiratory Global Medical Affairs, which encompasses both asthma and chronic obstructive pulmonary disease (COPD) therapeutic areas. Paraskevi Katsaounou is an assistant professor of pulmonary medicine at the Athens Medical School, and Stefan Frent is an assistant professor in the pulmonology department of the University of Medicine and Pharmacy in Timisoara, Romania. Paraskevi joined the asthma group and Stefan joined the COPD group in the Global Medical Affairs Novartis Respiratory team.

\section{The role of pharmaceutical companies in advancing research}

The role of pharmaceutical companies in advancing research has never been as broad and encompassing as it is today. A pharmaceutical company, through its medical and scientific staff, is dedicated to clinical research, product development and interactions with regulatory agencies. The medical affairs teams also work with other clinical colleagues on protocol design, grant and educational funding associated with research programmes, and the collection and analysis of clinical data. A well-knitted working relationship with academic and clinical medical institutions is indispensable to the creation of more effective means to control disease and manage patient's conditions. By supporting a dynamic exchange of ideas among the key influencers in today's healthcare delivery system, this harmony can create remarkable steps in improving the physician-patient relationship.
Cite as: Katsaounou $P$, Frent S. The ERS-industry fellowship: a tale of two experiences. Breathe 2018; 14: 13-17. 


\section{Paraskevi Katsaounou's experience}

Prior to undertaking an ERS Fellowship in Industry at Novartis, my picture of the pharmaceutical industry was different. It never occurred to me, as I experienced during this short period, that clinicians, academia and pharma could actually collaborate effectively and make the patient the winner.

Ultimately, the choice of taking up this kind of fellowship in an era characterised by so much hype in the media, involves many trade-offs. Expectations for such collaboration tend to differ, and in most situations finding areas of commonality where these individual expectations align perfectly has always been hectic [1]. While pharma's expectations are aligned with its strategy, clinicians per se want effective medical care for patients, reduced complexities in the use of pharmaceutical products, minimised adverse drug effects and minimal drug-drug interactions and academia clamours for improved prevention, diagnosis and treatment of diseases, research funding, abstracts and publications, lectures, talks, promotion, peer recognition and networking.

These differing expectations create a gap that can only be addressed via strategic collaboration between all players and this is what this fellowship offered.

Like every experience, there are known ups and downs, but of most importance is what one evaluates of the learning experience. Certain narratives tend to dissuade many physicians and academics from being a part of this collaboration for feared a skewed outcome, but evaluating the pragmatic benefit of close collaboration as revealed in this ERS fellowship, the whole experience could be described as a win-win case. The specific features and experiences that made my fellowship worthwhile are as follows.

1) International environment: the diverse international environment, which characterised my work setting, created a very warm and richly enabling environment for collaboration on common projects with people of different cultural perspectives.

2) Meeting new people: every meeting, both faceto-face and via teleconference, expanded my professional network; to meet with highly motivated and top experts working on different projects and be able to create a seamless and unrestricted network is an opportunity that is not available everywhere.

3) Access to academic resources, libraries and universities: having access to the amazing academic resources, as seen in the libraries, was a big plus to the fellowship. Usually a large subscription fee is needed to gain access to such resources as those I was able to access for free by virtue of this fellowship.

4) Understanding how the pharmaceutical industry works: I was unequivocally exposed to how the industry works in real life. Prior to this, my knowledge of the working of pharma was shallow. By working on different projects, I have been able to broaden my knowledge on the roles different functions/units play towards the effective development/launch of a product.

5) Teamwork and cross-functional collaboration: I collaborated with colleagues from different departments to ensure World Asthma Day event, in May, was a huge success. This experience brought to the surface the need to build good dynamics among team members if effectiveness in project execution is expected. The forthcoming Billion Breaths Campaign unveils similar collaborations, which makes the whole experience worthwhile. Moreover, the ongoing collaboration with high profile Novartis colleagues regarding the design of an asthma clinical trial is very gratifying.

6) Databases, seminars, training and certification on other medical and business software: the opportunity to use prestigious medical data from highly encrypted and rich databases and obtaining certificates following training in the use of specific software/databases was very beneficial.

7) Publications: as the medical expert in charge of the severe asthma patient survey, I was responsible for publishing the data, for delivering scientific congress presentations and am the first author of several publications [2-7] arising from the research/survey.

8) Being part of the Breathing event (series of scientific meetings whose programmes are agreed with an independent steering committee and organised/funded by Novartis), from the planning to the execution phase was very impressive as it gave me the chance to contribute, learn and network with top experts.

9) I was part of the team reviewing the Investigator Initiated Trials of Omalizumab (trials proposed to a pharma company by investigators who, therefore, become sponsors, as opposed to pharma led trials where the pharmaceutical company is the sponsor). It is was of paramount interest to understand how the team went about choosing to only agree on trials that addressed unmet scientific and clinical questions, and ensuring that the trials were conducted according to ethical elements and prioritising patients' safety and privacy rights.

The synergy created during this short-term collaboration was the most exciting aspect. It plays out that such synergy is best created when all players come together to advance a common goal (irrespective of their individual goals) and the patient becomes the winner. The World Asthma Day event, celebrated on the premises of Novartis, is an example of such synergy. The feedback from a severe asthmatic patient and representative from the patients' organisation was very satisfactory as she publicly lauded the brilliant idea of Novartis coming up with the World Asthma Day event to 
increase Novartis employees (across the whole organisation) awareness of such a common chronic disease. Such an effective outcome emanating from teamwork by different stakeholders led us achieve a patient-centric result.

As a strong advocate of the kind of collaboration that this fellowship presents, let me state that pharma cannot function independently of clinicians and at the same time, we (clinicians and academics) clearly need pharma to develop new treatments. Also, demonstrating efficacy and safety in clinical trials is essential for medications to be registered and appropriately licensed for further commercialisation.

Hence, it is important that in order to improve our practice and provide help for our patients, we should not remain passive in the decision making process that benefits the patient. This can be done either by circumspectly and carefully appraising any evidence presented to us independently, or by actively being a part of the team through a hybrid kind of employment.

In a nutshell, the fellowship has been characterised by both alluring benefits as well as challenges of a different nature and degree, which resulted in an overall net positive and very enriching experience.

\section{Stefan Frent's experience}

After qualifying as a medical doctor in 2004, a major challenge I had to face was the choice of a specialty; however, the fact that my father was also a pulmonologist and having the chance to spend 14 months as intern in the respiratory department of the Béziers Hospital in France, in the end, made me embrace the field of Respiratory Medicine. I joined the pulmonology department of the University of Medicine and Pharmacy "Victor Babes" Timisoara as assistant professor in 2008, completing my training as a respiratory physician in 2011 and obtaining a PhD in sleep medicine in 2014.

Being in an academic environment, I got the chance to be involved in different research and publishing activities quite early in my career, including participation as an investigator in more than 30 pharmaceutical clinical trials, mostly in asthma and COPD. While working on these trials, I was impressed by the rigorousness employed in the data collection process, as well as by the high standard of care provided for the patients enrolled in the trials, using state of the art tools for the diagnosis and monitoring of their respiratory conditions. It also represented a useful experience that enabled me to complete my PhD programme.

On this basis, it is not hard to guess the excitement I had to explore the opportunity to work in respiratory research in a big pharmaceutical company as part of the fellowship in industry offered jointly by ERS and Novartis. The announcement of the call for the applicants for this new type of fellowship drew my attention from the beginning and as I discovered that I matched the person specifications, I decided to apply for this fellowship. I was very happy to learn a few days later that I was one of the candidates selected by ERS for an interview at Novartis.

I started my adventure in the pharmaceutical industry working at the Novartis headquarters in Basel, Switzerland from July 2016, joining the COPD Global Medical Affairs Team in the Respiratory Franchise. The excellent facilities and working conditions, the smooth on-boarding process and the kindness of all the people I met in my first days at Novartis, really turned the stress of transitioning from a clinical setting to pharma industry into a pleasant experience.

One of the things I learned early during my fellowship was that teamwork is a key factor for delivering the best results in a highly competitive environment. I was very soon integrated in different teams working on specific projects. I was also assigned a direct supervisor, who acted like a mentor, managing my questions, my expectations and guiding my work, and to whom I was accountable for accomplishing my tasks.

To summarise some of the main activities in which I have been involved during this fellowship, I would mention medical monitoring activities in a phase IV global clinical trial for COPD patients. I was able to explore different research tools, such as post hoc analysis, network meta-analysis, data mining etc., and I was involved in the data dissemination process including data interpretation, messaging, development of abstracts/manuscripts and delivering medical communication. In addition, I shadowed senior colleagues during the preparation of the Novartis COPD Symposium at the ERS International Congress.

By monitoring and reviewing the clinical trial data, I was able to combine my experience as a clinician and former investigator in clinical trials with the ability to understand and address specific issues from investigative sites as well as to obtain a good perspective of what it means to conduct a global trial and ensure patients' safety at all times during their participation in a clinical research project. At the time I joined Novartis, the trial was already ongoing; however, it was still in the recruitment phase. This allowed me to see the progression of the trial through all its subsequent phases and to have an active role in different specific activities related to these phases. I should also mention here that, courtesy of my Novartis superiors and with ERS's approval, I was offered the chance to have an extension of my fellowship in order to be able to finish the projects in which I have been involved, including seeing the results of the clinical trial and preparing their publication.

Working in a Medical Affairs team provided an ideal environment to explore a variety of additional data generation methods. I was able, for example, 
to develop my knowledge and understanding of the network meta-analysis (NMA) tool while working on a project comparing different inhaled medications for COPD currently available on the market. While the data for direct comparisons between the combination therapies was lacking, the project focused on getting more information on their comparative efficacy using a NMA model (indirect comparison). I was involved in the review of the output of this project and contributed to the development of an abstract that was presented during the American Thoracic Society (ATS) congress in 2017.

One of the things I was most excited about was looking at the data provided by the statisticians as a primary or secondary output of a study, trying to interpret and develop a relevant scientific message to be further communicated internally, within Novartis and externally (as scientific publications). During various team meetings, it was very instructive for me to hear the opinions of senior colleagues on the interpretation of data, shaping of the main scientific message and the decision on how (abstract or manuscript) and what to publish from the statistical dataset.

Coming from an academic position, I was very interested to improve my skills in developing scientific publications. Therefore, I really enjoyed working in collaboration with medical writers and other co-authors on the development of several abstracts and manuscripts. Again, the inputs from the senior colleagues as well as the interaction with the external co-authors (international medical experts in respiratory medicine) provided very useful insights for my understanding of the whole process. I am very pleased to count among other accomplishments of this fellowship co-authorship of five abstracts [8-12] presented during ATS and ERS Congresses, and four manuscripts.

Shadowing a senior colleague during the preparation of the Novartis COPD Symposium for the ERS International Congress was another exciting experience, which allowed me to assist and provide input on the scientific content as well as getting the chance to interact with the medical experts in respiratory medicine invited to be the speakers for the Novartis Symposium.

I should not forget to mention also the wealth of valuable training materials, medical literature and webcast conferences that we were given access to, as well as the chance to attend the two most recent ERS International Congresses. All these played a significant role in the consolidation of my training as a physician and researcher.

A year of working in pharmaceutical industry within the framework of a fellowship similar to the one offered by ERS is, in my opinion, definitely a worthwhile experience, which I would warmly recommend to any practitioner with interest in pharmaceutical research. As already mentioned by my colleague, I confirm that this kind of experience provides an ideal opportunity to get the best insight into how the pharmaceutical industry works and how it connects with academia and prescribing physicians. Even before joining Novartis, I was already aware that the interactions of the pharmaceutical industry with healthcare providers are highly regulated due to a general negative perception of the influence pharma could exert on prescribing physicians in order to promote its products. I must confess though that this kind of perception is lacking in the environment where I come from, being replaced by the general recognition of the fact that without the medicines provided by the pharma industry we would not be able to treat our patients.

While working at Novartis, I was able to observe a continuous and sustained effort to comply with all applicable laws and regulations, at both global and country level, and the high value placed on integrity and good external reputation.

This fellowship experience had also its difficulties (e.g. moving to a foreign country with the whole family and adapting to a new culture, which is not always easy). I also admit that the office work sometimes lacked the vibrancy of a clinical setting and direct contact with patients; however, the benefits of this programme far outweighed any inconveniences.

An even bigger challenge is the decision to join the pharmaceutical industry for a lifetime career. It depends of course on personal preferences and the ability to adapt to a strong business environment and a very competitive landscape. Anyone being in the position to make this choice should carefully balance the advantages and disadvantages of this kind of job to make the best out of his/her own resources.

In summary, I strongly believe that this fellowship offers a unique opportunity to get first-hand insights into the world of pharmaceutical industry and establish connections with relevant people for a potentially lifelong impact on your future career.

\section{Summary}

From the level of contentment in our narratives, it is imperative to advise all new and aspiring fellows: this fellowship was definitely worth the time. Once the opportunity opens up for you, do not hesitate to fill in. Undoubtedly, like us, upon completion, you will be telling your own beautiful tale of the escapade.

\section{Acknowledgements}

We are indebted in appreciation to Pascal Pfister, the senior coordinator of this fellowship, for making this project become a reality; to Robert Fogel, Michael Larbig and Xavier Jaumont (our supervisors) for their kind and competent mentorship; to Caroline Schumacher, our administrative expert, for her precious help in all the administrative 
matters; to Kostas Kostikas for giving us the impulse to write this paper and for his kind support throughout the fellowship; and to all our colleagues from the Medical Affairs, Development and Commercial departments for providing a very friendly environment, allowing for a quick integration and making us feel a part of the whole Novartis Respiratory team.

\section{Conflict of interest}

P. Katsaounou has received honoraria, and advisory and travel expenses from Pfizer, Chiesi, Boehringer Ingelheim, GlaxoSmithKline and Novartis. S. Frent reports personal fees (speaker fees) from Astra Zeneca and Boehringer Ingelheim, and accommodation and travel expenses for the ERS Congresses in 2016 and 2017 from Novartis, all outside the submitted work; he is a Former European Respiratory Society Fellow at Novartis.

\section{References}

1. Birnbaum JM. Pharma and academia: what we have here is a failure to communicate. Cell Metab 2016; 24: 365-367.

2. Katsaounou P, Conde LG, Kroegel C, et al. The challenges of living with severe asthma in Europe. Allergy 2017; 72: Suppl. S103, 393.

3. Katsaounou P, Hyland ME, Gasser M, et al. Perceived and actual control in patients with severe asthma: results from a global online survey. Eur RespirJ 2017; 50: Suppl. 61, PA4689.

4. Katsaounou P, Hyland ME, Conde LG, et al. Are severe asthmatics still smoking? Eur Respir J 2017; 50: Suppl. 61, PA2985.

5. Katsaounou P, Conde LG, Kroegel C, et al. Living with severe asthma year 2016. Eur RespirJ 2017; 50: Suppl. 61, PA4682.

6. Alvares L, Kumar P, Muthukumar M, et al. PRS75: Population health impact of Omalizumab over 15 years of experience in moderate to severe allergic asthma. ISPOR 20th Annual European Congress 2017. Glasgow, November, 4-8, 2017.

7. Katsaounou P, Gavornikova M, Hyland ME, et al. Paediatrics and adolescents living with severe asthma in the year 2016: Results of a global survey. Pediatric Allergy and Asthma Meeting PAAM 2017. London, October 26-28, 2017.
8. Fogel R, Sayre T, Franek J, et al. Comparative efficacy of inhaled bronchodilator combination therapy in stable COPD. Am J Respir Crit Care Med 2017; 195: A5478.

9. Wedzicha JA, Patalano F, Shen S, et al. Early occurrence of any COPD exacerbation predicts further higher risk of moderate/ severe exacerbations regardless of recording tool: the FLAME study. Eur RespirJ 2017; 50: Suppl. 61, PA3254.

10. Roche N, Wedzicha JA, Patalano F, et al. COPD exacerbations significantly impact quality of life as measured by SGRQ-C total score: results from the FLAME study. Eur Respir J 2017; 50: Suppl. 61, OA1487.

11. Wedzicha JA, Chapman KR, Frent SM, et al. Indacaterol/ glycopyrronium (IND/GLY) reduces days with COPD exacerbation vs salmeterol/fluticasone (SFC) independent of PRO tool: results of the FLAME study. Eur Respir J 2017; 50: Suppl. 61, PA1803.

12. Roche N, Chapman KR, Frent SM, et al. Indacaterol/ glycopyrronium (IND/GLY) improves lung function, health status and rescue medication use vs salmeterol/fluticasone (SFC) independent of symptom response: The FLAME study. Eur RespirJ 2017; 50: Suppl. 61, PA724. 